\title{
CAPILLARY BLOOD PRESSURE IN MAN. DIRECT MEASURE- MENTS IN THE DIGITS DURING ARTERIAL HYPERTENSION INDUCED BY PAREDRINOL SULFATE ${ }^{1}$
}

\author{
By LUDWIG W. EICHNA \\ (From the Department of Medicine, The Johns Hopkins University School of Medicine, \\ Baltimore)
}

(Received for publication June 1, 1942)

A previous study (1) indicated that the digital capillary blood pressure was approximately equal in both normal and hypertensive subjects, not only during the resting state, but also during physiologically induced vasoconstrictions and vasodilatations. It was the purpose of this investigation to determine what happened to digital capillary blood pressure when hypertension was induced in subjects with normal arterial pressures.

\section{METHODS}

General. As in previous studies $(1,2,3)$, all determinations of capillary blood pressure were made on capillaries in the nail-folds of the fingers. The direct microinjection method (Landis) (4), modified as previously described (2), was employed. The general methods, conditions, and precautions employed were fully described in a previous communication (2).

Particular. At both the normal and elevated levels of arterial pressure, capillary blood pressure was always determined in the same location of the same capillary. Both levels of arterial pressure were obtained during a single observation period, throughout which the digital skin temperature was maintained constantly at levels of moderate digital vasodilatation (2). Temporary arterial hypertension of 45 to 60 minutes duration was produced by the intramuscular injection of $20 \mathrm{mgm}$. to $30 \mathrm{mgm}$. of paredrinol sulfate. ${ }^{2}$ This method was chosen because the hypertension thus produced is not accompanied by a significant alteration in cardiac output, velocity of blood flow, basal metabolic rate (5), or skin temperature (6). Moreover, others have suggested that the hypertension induced by paredrinol sulfate “. . . presents a condition resembling clinical hypertension ..." (5).

The technical difficulties encountered in determining repeatedly the capillary blood pressure in the same location of a given capillary, limited these observations chiefly to the large capillaries of patients with Raynaud's disease and scleroderma. One normal subject, 2 patients with Raynaud's disease, and one with scleroderma served for this study.

1 Supported by a grant from The Commonwealth Fund for the study of essential hypertension.

2 The paredrinol sulfate was kindly supplied by The Smith, Kline and French Laboratories.
All interruptions of the sympathetic innervation to the fingers were accomplished by operative preganglionic sympathectomy according to the method of Smithwick $(7,8)$.

\section{RESULTS}

Normal sized capillaries-Normal subject

During the temporary hypertension induced in one normal subject, the digital capillary blood pressure in 3 capillaries remained within the limits determined for this subject when his arterial pressure was normal (Figure 1). The hypertension was associated with a decrease of $2 \mathrm{~mm}$. $\mathrm{Hg}$ to $7 \mathrm{~mm}$. $\mathrm{Hg}$ in the capillary blood pressure in these capillaries. In the arteriolar limb of a fourth capillary, the pressure rose by $19.5 \mathrm{~mm}$. $\mathrm{Hg}$ (Figure 1).

\section{Abnormally large capillaries}

Sympathetic innervation intact. With the mean arterial pressure elevated to 140 to $150 \mathrm{~mm}$. $\mathrm{Hg}$, the digital capillary blood pressure usually differed but slightly from that determined in the same 3 individuals at their normal mean arterial pressures of 100 to $110 \mathrm{~mm}$. $\mathrm{Hg}$ (Figure 1). In 7 summits and venous limbs, the difference amounted to $-7.5 \mathrm{~mm}$. $\mathrm{Hg}$ to $+10.0 \mathrm{~mm}$. $\mathrm{Hg}$, and in one arteriolar limb, to $+22 \mathrm{~mm}$. $\mathrm{Hg}$ (Figure 1). Only this latter value exceeded the limits established for these subjects when their arterial pressures were normal.

In 4 capillaries of 1 subject, the digital capillary blood pressure was determined during the induced hypertension and then redetermined at the height of the erythema of a histamine-flare, produced at the peak of the hypertension. During the histamine-flare, the digital capillary blood pressure increased by $8 \mathrm{~mm}$. $\mathrm{Hg}$ to $17 \mathrm{~mm}$. $\mathrm{Hg}$ (Figure 1). The resultant values tended to exceed the upper limits established under resting conditions in the same portions of these capillaries at normal and elevated arterial pressures. 


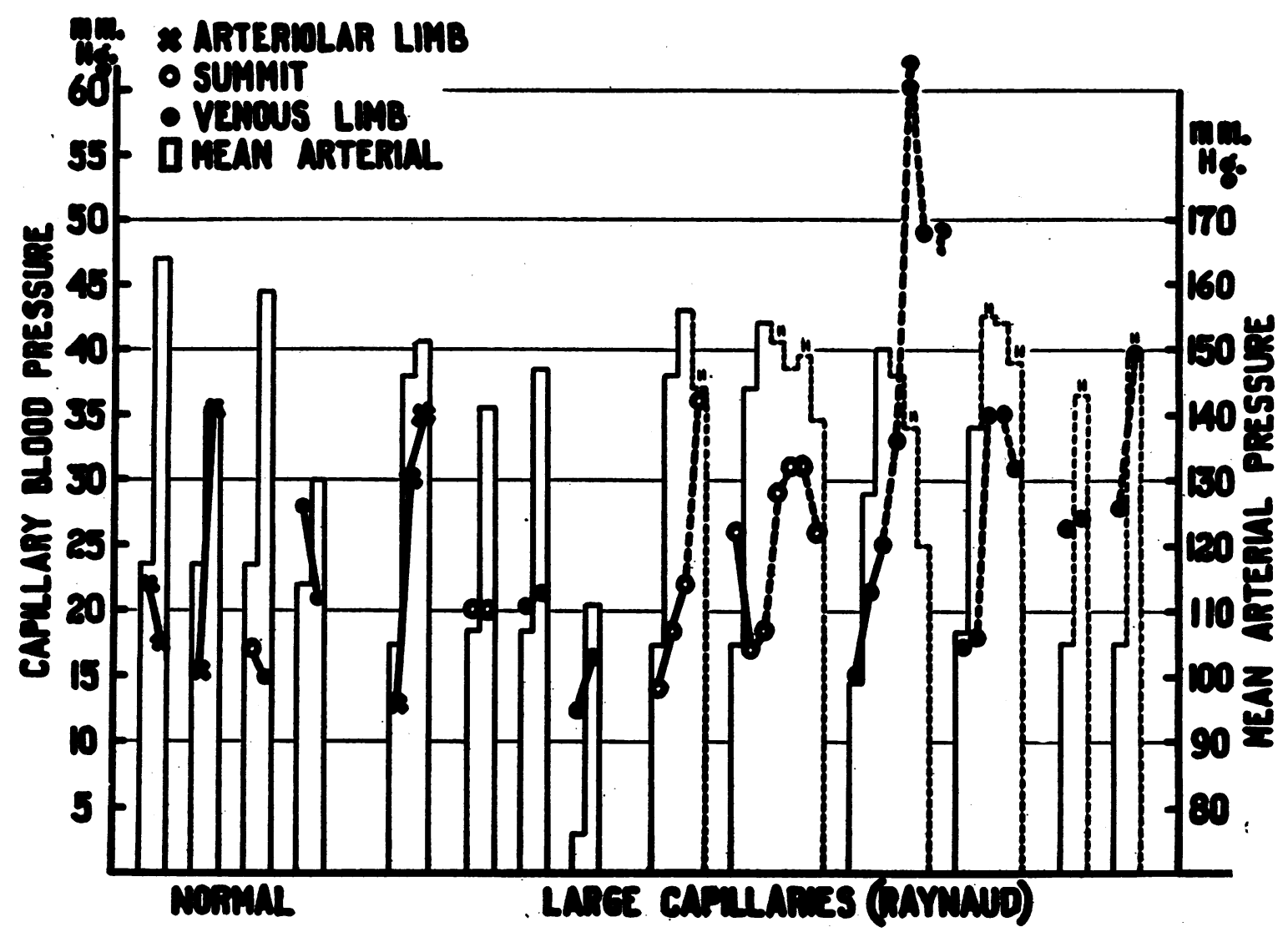

Fig. 1. Relation Between Mean Arterial Pressure and Digital Capillary Blood Pressure Concurrently Determined in the Same Capillary at Normal and Induced Hypertensive levels of Arterial Pressure. Digital Innervation Intact.

First 4 determinations in normal sized capillaries of one normal individual. All other determinations in abnormally large capillaries of 3 subjects with Raynaud's disease and scleroderma. The two values noted with a question mark may have been "arteriole" pressures rather than capillary blood pressures.

\section{Both charts are similarly plotted.}

The ordinates indicate in $\mathrm{mm}$. $\mathrm{Hg}$ digital capillary blood pressure and mean arterial pressure. Along the abscissae, each unit of the graph represents a single capillary. The key in the upper left hand corner gives the symbols representing each type of blood pressure.

The change in mean arterial pressure is indicated by the change in height of the white column. The change in digital capillary blood presure is indicated by the darker line connecting the various symbols for capillary blood pressure. At all times, concurrent determinations of capillary blood pressure and mean arterial pressure are plotted in the same abscissal space.

Determinations under resting conditions are connected by solid lines. Determinations during local vasodilatation are indicated by the dotted lines. When vasodilatation was induced by histamine, there is a small $H$ above the white column, when produced by reactive hyperemia, a small $R$ tops the column.

The final values did not exceed the range previously determined in a larger group of subjects with normal arterial pressures (3).

Sympathetic innervation interrupted. Similar results were obtained on the same 2 patients with Raynaud's disease after preganglionic sympathectomy of the upper extremity. When the arterial pressure increased from normal to hypertensive levels, digital capillary blood pressure in 5 capillaries changed by $-2 \mathrm{~mm}$. $\mathrm{Hg}$ to $+7 \mathrm{~mm}$. $\mathrm{Hg}$ (Figure 2). Again, the final values remained within the range established for these subjects when their arterial pressures were normal.

During the erythema of histamine-flares, pro- 
duced at the peak of the hypertension, digital capillary blood pressure in 3 capillaries rose 4 $\mathrm{mm}$. $\mathrm{Hg}, 9 \mathrm{~mm}$. $\mathrm{Hg}$, and $13 \mathrm{~mm}$. $\mathrm{Hg}$ (Figure 2) above the resting values, obtained at both normal and elevated arterial pressures. When reactive hyperemia was produced at the height of the hypertension, digital capillary blood pressure was less altered, changing by $-1 \mathrm{~mm}$. $\mathrm{Hg}$ to $+4 \mathrm{~mm}$. $\mathrm{Hg}$ in 3 capillaries and by $+13 \mathrm{~mm} . \mathrm{Hg}$ in a fourth (Figure 2). As a result, the final values, obtained during the histamine-flares at hypertensive arterial pressures, tended to exceed the limits of capillary blood pressure for these patients at their normal and hypertensive pressures. During reactive hyperemia at hypertensive arterial pressures, the final capillary blood pressures were not significantly altered from the resting values at normal arterial pressures.

\section{DISCUSSION}

Since the experiments are few and the data not entirely uniform, general conclusions are not warranted. However, it did seem of interest that paredrinol sulfate produced in normal individuals a hypertension during which the digital capillary blood pressure remained essentially unchanged. This indicates an increased vascular resistance of precapillary origin, probably arteriolar in location. Since the digital capillary blood pressure during the hypertension induced by paredrinol was normal and approximately equal whether the digits were sympathectomized or whether their innervation was intact, the increased vascular resistance (and hypertension) was not produced by mediation of the sympathetic nervous system, at least not in so far as the fingers are concerned.

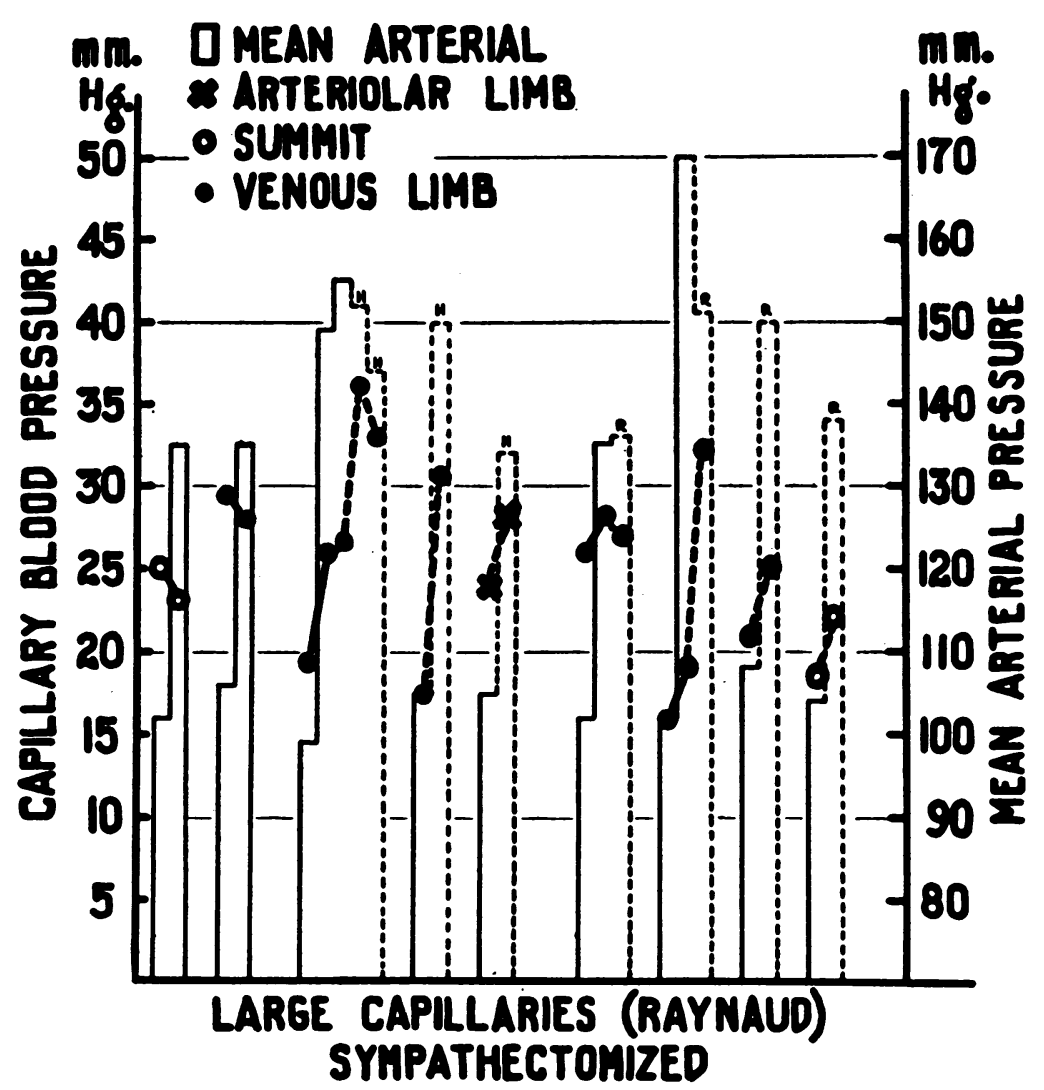

Fig. 2. Relation Between Mean Arterial Pressure and Digital Capillary Blood Pressure Concurrently Determined in the Same Capillary at Normal and Induced Hypertensive Levels of Arterial Pressure. Preganglionic Sympathectomy of Digits

All determinations in abnormally large capillaries of 2 subjects with Raynaud's disease. 
In several respects, the digital capillary blood pressure during hypertension induced by paredrinol was similar to that in essential hypertension. Each period of hypertension was associated with a normal digital capillary blood pressure; an indication of an increased vascular resistance of precapillary origin. Each hypertensive phase was characterized by a failure of the digital capillary blood pressure to rise significantly during the vasodilatation of reactive hyperemia, though a considerable increase in pressure followed the local injection of histamine. Apparently histamine released, at least to some extent, the increased vascular resistance in the digits, whereas reactive hyperemia failed to do so.

These points of similarity are not sufficient justification for considering the mechanism of essential hypertension to be similar to that induced by paredrinol sulfate. Other types of hypertension may produce similar changes in the digital capillary blood pressure.

\section{SUMMARY}

1. During the hypertension induced by paredrinol sulfate in subjects with normal arterial pressures, the digital capillary blood pressure remained within the limits previously established for the same individuals when their arterial pressures were normal.

2. This finding maintained equally for capillaries in digits with intact innervation and after preganglionic sympathectomy.

3. At the height of the paredrinol-induced hypertension, the vasodilatation of local reactive hyperemia did not significantly alter the digital capillary blood pressure. The hyperemia of the histamine-flare was usually associated with a rise in the digital capillary blood pressure to values which just exceeded the pressures obtained during the resting state at both normal and elevated arterial pressures.

The author wishes to thank Dr. Harris B. Shumacker, Jr., for performing the preganglionic sympathectomies of the upper extremity, and $\mathrm{Mr}$. William A. Oktavec, Jr., and Miss Margot Robinson for technical assistance during the study.

\section{BIBLIOGRAPHY}

1. Eichna, L. W., and Bordley, J., III, Capillary blood pressure in man. Comparison of direct and indirect methods of measurement. J. Clin. Invest., 1939, 18, 695.

2. Eichna, L. W., and Wilkins, R. W., Capillary blood pressure in man. Direct measurements in the digits during induced vasoconstriction. J. Clin. Invest., 1942, 21, 697.

3. Eichna, L. W., and Bordley, J., III, Capillary blood pressure in man. Direct measurements in the digits of normal and hypertensive subjects during vasoconstriction and vasodilatation variously induced. J. Clin. Invest., 1942, 21, 711.

4. Landis, E. M., Microinjection studies of capillary blood pressure in human skin. Heart, 1930, 15, 209.

5. Stead, E. A., Jr., and Kunkel, P., Mechanism of the arterial hypertension induced by paredrinol $(a-N$ dimethyl-p-hydroxyphenethylamine). J. Clin. Invest., 1939, 18, 439.

6. Abbott, W. O., and Henry, C. M., Paredrine ( $\beta-4$-hydroxyphenylisopropylamine). A clinical investigation of a sympathomimetic drug. Am. J. M. Sc., 1937, 193, 661 .

7. Smithwick, R. H., Modified dorsal sympathectomy for vascular spasm (Raynaud's disease) of the upper extremity. A preliminary report. Ann. Surg., 1936, 104, 339.

8. Smithwick, R. H., The value of sympathectomy in the treatment of vascular disease. New England J. Med., 1937, 216, 141. 